\title{
A Research on the Risk Measure of Chinese Copper Futures Market Based on VaR
}

\author{
Hu'e Zhao \\ School of Economics and Management, Shanxi University, Taiyuan, China \\ Email: 2304297131@qq.com
}

Received April 2014

\begin{abstract}
Measuring the risk of the Chinese Copper futures market is the key point of the risk management. Based on the normal distribution, T-distribution and GED-distribution, this paper measures the VaR values of the risk of the copper futures by GARCH and EGARCH models. Using empirical testing, it shows the EGARCH-N model can characterize the market risk of the copper futures more precisely than other types of models.
\end{abstract}

\section{Keywords}

Copper Futures, VaR-CARCH, Market Risk

\section{Introduction}

The basic function of the futures market is to avoid the risk of price fluctuations in the spot market. Because of the special trading system and operation rules, the futures market also introduces some new risk. As there are not only hedgers, but lots of speculators, the futures market itself contains huge risk. Speculation may bring huge volatility to the price of the futures making the futures market is more risky than the spot market. Secondly, the price volatility of the futures market maybe can be delivered to the spot market, then increase the volatility of the spot market price. Thus we need more strict risk control and management measures for the futures market. And how to measure the risk of the futures market accurately has become the key of risk management of futures market.

\section{Literature Review}

In financial investment, the risk is a major concerned topic. July 1993, G30 group firstly proposed the VAR approach to measure the market risk, on the basis of financial derivative products. After a few years, VaR has become the mainstream of the financial market risk measurement methods. Dowd and Kewin (1999) [1] proposed that $\mathrm{VaR}$ is an extreme value model that only modeling the tail of the yield distribution which exceed a certain threshold to calculate the value of VaR, not the distribution of the entire asset portfolio yield. Christoffersen and Errunza (2000) [2] pointed out that the traditional VaR measurement method, always using the normal distribution assumption, is not appropriate. In order to fit distribution characteristics of the fat tail of financial time series data, Bollerslev (1986) [3] proposed the generalized conditional heteroskedasticity models (GARCH model) 
and Nelson (1990) proposed exponential GARCH model (EGARCH model) [4]. Both of them were gradually applied to the VaR risk measure of the asset portfolio. However, Anderson (2001) [5] pointed out: VaR does not provide any information on the tail of capital gains, so that the portfolio may suffer huge losses. And VaR risk measure is not compatible, because of that the diversification will not necessarily spread risk. In addition VaR is non-smooth and non-convex function of portfolio returns, which contain multiple local minima. All of them brought inconvenience to investment optimization. Then, Rockafellar and Uryasev (2002) [6] proposed the conditional Value-at-risk (CVaR) that solve the problem of non-additive. And furthermore, Alexander, Coleman and $\mathrm{Li}$ (2006) [7] found that there are morphological variation CVaR phenomenon, when optimize the combination of derivatives hedging portfolio by $\mathrm{CVaR}$. And then, after the introduction of a certain percentage of the cost can improve that phenomenon.

\section{The Calculation of VaR Based on GARCH Model}

This paper calculates VaR based on the parameter method of normal, T and GED distribution. Firstly, the key of the calculation of $\mathrm{VaR}$ is to calculate the volatility. Many studies have found financial assets yield time series, whose volatility exhibit clustering, conditional heteroscedasticity and leverage, are not normally distributed, but perform the characteristics of a fat tail. In order to estimate the financial risk precisely, it is needed to fully consider the distribution of returns and their volatility.

$\mathrm{VaR}$ is the potential maximum loss that the portfolio faces, under normal market conditions, within a given confidence level and holding period.

Assume that the initial value of the portfolio as $\mathrm{W}$, the expected return rate in the end of holding period is $\mathrm{R}$. The mathematical expectation and the standard deviation of $\mathrm{R}$ is $\mu$ and $\sigma$. And then, at a given confidence level $c$, the minimum value of the portfolio is: $w^{*}=w\left(1+R^{*}\right)$, where $R^{*}$ is the appropriate minimum rate of return, then:

$$
\operatorname{VaR}=E(w)-w^{*}=-w\left(R^{*}-\mu\right)
$$

If $\alpha$ is the quantile corresponding to the confidence level c at a certain distribution, then $R^{*}=\mu-\alpha \sigma$, and then:

$$
\operatorname{VaR}=E(w)-w^{*}=-w\left(R^{*}-\mu\right)=-w(\mu-\alpha \sigma-\mu)=\alpha \sigma w
$$

Assume that the probability density function of portfolio returns for the future is $f(w)$, then the minimum value for the portfolio $w^{*}$ under certain confidence level $c$ is:

$$
c=\int_{w^{*}}^{+\infty} f(w) \mathrm{d} w
$$

VaR is generally calculated by parameter method, historical simulation method and Monte Carlo simulation method, we choose one of them: parametric method. In addition, GARCH family model, which has sustained variance and the capabilities of processing heavy tail, can describe the sequence of financial events precisely.

In order to characterize the fat tail, some scholars proposed using t or GED distribution to describe the distribution of the return series. In order to capture the conditions heteroscedasticity they proposed to use ARCH models. But in practice, it needs great lag order to get better fitting results for the ARCH model. As the lag structure of the GARCH model is more flexible than the ARCH model, we can use the GARCH model to resolve that problem. In addition, when you want to portray an asymmetric effect the stock market, the EGARCH model can accurately describe the situation of the financial products' price fluctuations.

\section{An Empirical Analysis of the Copper Futures Market Risk}

\subsection{Data}

Considering that: firstly copper futures, which develop soundly and trade actively, has a strong representation; secondly, copper futures without significant seasonal effects and period effects can easily exclude the influence of other factors in the analysis of data; finally, as copper futures carry a longer time, more comprehensive and reliable data can been obtained, we choose the copper futures from the Shanghai Futures Exchange as the representative to research the risk of China's commodity futures market.

We construct the data of the continuous cooper futures price with the method of selecting the most active contracts which also are named the main contracts determined by positions and trading volume. And then we 
take daily closing price of the most active monthly copper futures which contain a total of 487 observations as the observed object to analysis their risks and features among the period of January 4, 2011 to December 31, 2012. Data analysis tools are used here contain Eviews 6.0 and EXCEL2010.

\subsection{Analysis of Characteristics of the Data}

We select the logarithmic returns of futures daily closing prices to portray the volatility, namely:

$$
R(t)=\operatorname{Ln} P_{t}-\operatorname{Ln} P_{t-1}
$$

where $R(t)$ represents the logarithmic return series of copper futures price, $P_{t}$ represents the closed price of copper futures in date of $t$.

We can clearly see from the Figure 1: the price tumbled in highs from January 2011 and touched the bottom in May 2012, and then rose slightly, but just kept in 60,000 or less. Overall, the volatility of cooper futures price is relatively large. This could own to the dramatic changes in the demand of copper. From Figure 2 we can see that: the logarithmic yields fluctuate frequently at around zero. And the large fluctuations are followed by large fluctuations, and the small fluctuations are followed by small fluctuations. That means there is conditional heteroscedasticity and clustering feature in the copper yields sequence. Therefore, we use GARCH and EGARCH model to estimate VaR dynamically in order to overcome the conditional heteroscedasticity.

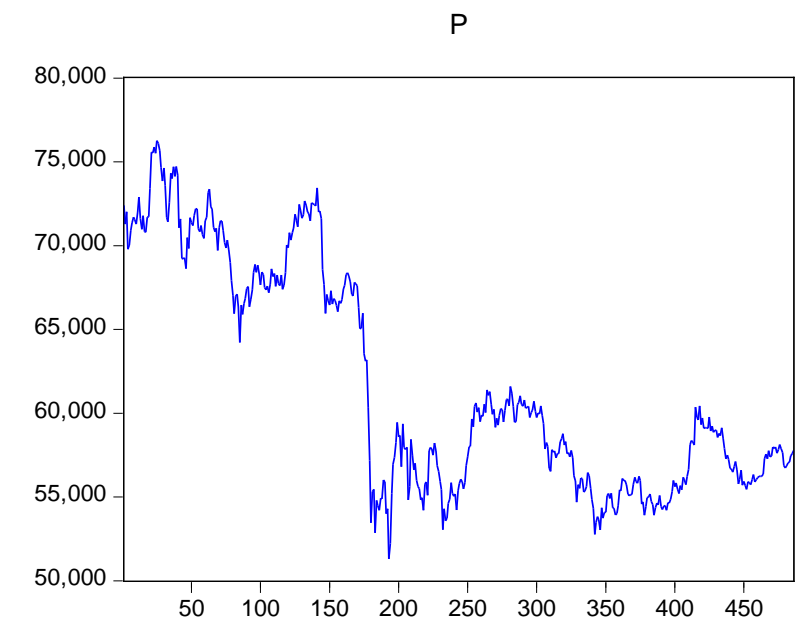

Figure 1. The daily closing price of copper futures.

$\mathrm{R}$

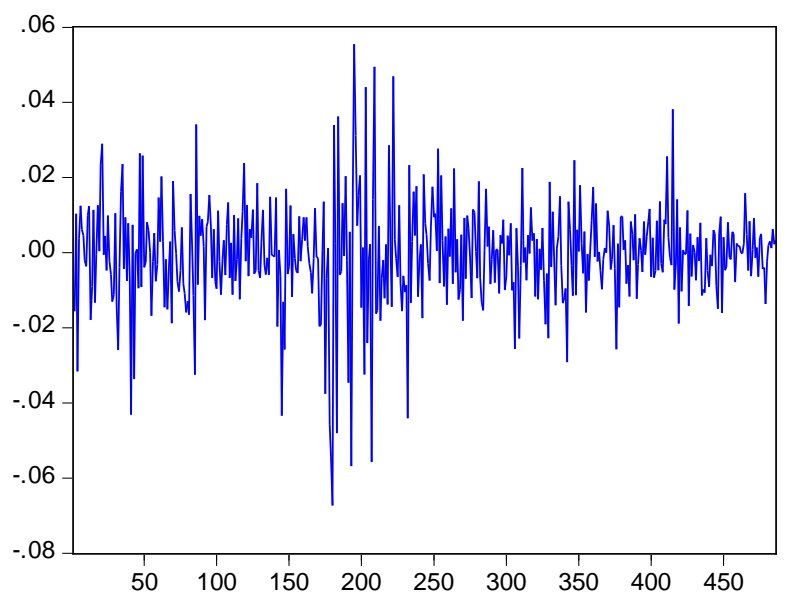

Figure 2. Fluctuations of logarithmic return series of copper futures. 
From Figure 3: the skewness of the logarithmic return series is -0.445876 , which is less than zero and left side; the kurtosis of series is 6.630957, larger than the normal kurtosis 3 and JB value is very significant. From that the data is not completely normal distribution, but has some fat tail. Owning to the return series are not entirely normal distribution, we will fit GARCH and EGARCH equation under the conditions of normal distribution, $\mathrm{T}$ distribution and GED distribution.

One of the requirements of using GARCH model is a sequence of data must be stable. Stability refers to the explanatory variables in regression model regress the mean value, and that also means the regression equation without a unit root. We use ADF unit root test method to test the stability of the logarithmic return series of copper futures. The results are in Table 1.

As we can be seen from the above test results, ADF value is - 23.58625, less than the threshold under the confidence level of $1 \%, 5 \%$ and $10 \%$, and the probability is zero. Therefore the null hypothesis of the existence of a unit root is denied, indicating that the logarithmic return series is stable.

Prior to the return series modeling we also need to test whether there is autocorrelation. The inertia and viscosity of series can cause autocorrelation, and lead the series residuals associated with other residuals. We use the autocorrelation and partial autocorrelation plot diagram to test autocorrelation.

Considering the AC, PAC, the Q statistic and the probability from the test results (Table 2), under the significant level of 5\%, there are not autocorrelation from the first-order lag to the fifth. But to the higher order lag the hypothesis of zero correlation is rejected meaning there are autocorrelation. However at the significance level of $1 \%$, higher-order lags basically can be considered non-existent autocorrelation. Therefore, we build a white noise model for yields sequence.

One prerequisite for the establishment of GARCH model is the presence of ARCH effective for time series. Previously we roughly judged the presence of conditional heteroscedasticity in yields series, and now we test it more precisely.

As can be seen from the results in Table 3, the value of AC and PAC are not zero, and the Q statistic is very large, so the null hypothesis of zero correlation coefficient is rejected. Therefore there is high-order ARCH effective for residuals, namely GARCH effects. So we can establish GARCH model for yield series.

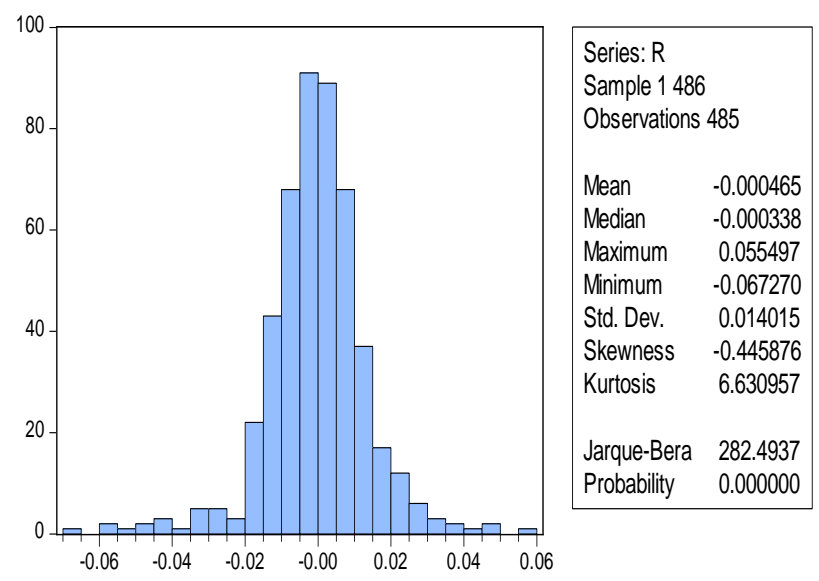

Figure 3. The normality test of logarithmic return series of copper futures.

Table 1. ADF unit root stable test results of the logarithmic yield series.

\begin{tabular}{ccc}
\hline Table Head & T-Stat & Prob \\
\hline ADF-Stat & -23.58625 & 0.0000 \\
$1 \%$ & -3.443635 & -2.867292 \\
$5 \%$ & -2.569896 \\
$10 \%$ & \\
\hline
\end{tabular}


Table 2. Correlation analysis of logarithmic yield series.

\begin{tabular}{ccccc}
\hline Lag order & AC & PAC & Q-Stat & Prob \\
\hline 1 & -0.070 & -0.070 & 2.4205 & 0.120 \\
2 & 0.022 & 0.017 & 2.6633 & 0.264 \\
3 & 0.088 & 0.091 & 6.4744 & 0.091 \\
4 & -0.067 & -0.056 & 8.6846 & 0.069 \\
5 & 0.046 & 0.034 & 9.7178 & 0.084 \\
6 & -0.127 & -0.128 & 17.611 & 0.007 \\
7 & 0.041 & 0.035 & 18.432 & 0.010 \\
8 & -0.019 & -0.021 & 18.610 & 0.017 \\
10 & -0.037 & -0.013 & 19.296 & 0.023 \\
\hline
\end{tabular}

Table 3. ARCH effective test of logarithmic yields.

\begin{tabular}{ccccc}
\hline Lag order & AC & PAC & Q-Stat & Prob \\
\hline 1 & 0.268 & 0.268 & 35.095 & 0.000 \\
2 & 0.292 & 0.238 & 76.928 & 0.000 \\
3 & 0.161 & 0.043 & 89.638 & 0.000 \\
4 & 0.240 & 0.149 & 117.93 & 0.000 \\
5 & 0.126 & 0.007 & 125.80 & 0.000 \\
6 & 0.101 & -0.019 & 130.83 & 0.000 \\
7 & 0.035 & -0.040 & 131.46 & 0.000 \\
8 & 0.089 & 0.041 & 135.38 & 0.000 \\
10 & 0.094 & 0.061 & 139.76 & 0.000 \\
\hline
\end{tabular}

\subsection{The Calculation of VaR}

We calculate the VaR of the cooper futures respectively using GARCH and EGARCH model based on the normal distribution, $\mathrm{T}$ distribution and GED distribution. Within the comparative analysis and the test of VaR, we find the optimal model that fit the measurement of copper futures market risk. In the following we respectively estimate the parameter of $\operatorname{GARCH}(1,1)$ and $\operatorname{EGARCH}(1,1)$ in three distributions.

According to the results showed in the Table 4, in addition to the $\alpha_{0}$, the likelihood estimators, meeting the test of the significance level of $5 \%$, are large. That means they can describe the autocorrelation of yields fluctuations precisely, so all of them can be used as analysis tools of stock volatility. The $\alpha_{0}$ parameter is close to zero, reflecting the equilibrium level of returns in cooper futures markets is negative. The parameter of $\alpha_{1}$ is greater than zero, reflecting the clustering characteristics of price volatility. All of the above manifest the speculation of futures market. Except the EGARCH-T model, the $\beta$ is significantly greater than the $\alpha_{1}$ in the conditional variance equation of other models, which means the market affected by the accident information largely. The value of $\alpha_{1}+\beta$ are relatively close to 1 , indicating that the volatility of copper futures market is persistent and the current information is very important to predict future conditional heteroskedasticity. In the EGARCH model, the parameter $\gamma$ is less than zero, indicating that the impact of bad news to the price volatility is greater than the good news. 
Putting the quantile calculated in Table 5 and the conditional standard deviation according by GARCH model and EGARCH model into the formula given above to calculate the VaR, we can get 484 values of VaR under different distributional assumptions.

\subsection{The VaR-Test Based on Failure Rate}

Generally method of validity test of VaR models is to compare actual losses and expected losses. If the model is valid, the simulated failure rate should be very nearly equal to the preset significance levels, on the contrary, if the failure rate is different to the significance level largely, the model is not suitable.

Under the null hypothesis, LR statistic is $\chi^{2}$ distribution of degrees of freedom is 1 . At the confidence level of 95\%, its threshold is 3.841, and at the confidence level of 99\%, its threshold 6.635. Accordingly, if LR statistic is larger than 3.841 or 6.635 at those two confidence levels, this model is rejected, otherwise, is accepted.

As can be seen from Table 6, at 95\% confidence level, only GARCH-T, EGARCH-N and EGARCH-T model passed the test. Comparing the three models, the actual failed days of EGARCH-N is closer to the expected failed days, which means it can measure the risk precisely. However at the $99 \%$ confidence level, all the models can not passed the test. Owning to the actual failed days are more than the expected failed days, all the models above underestimate the risk. So at the higher confidence level, the models are easier to underestimate the risks. However, in our paper, the theoretical optimal model has not been validated, and the optimal model is

Table 4. Correlation analysis of logarithmic yield series.

\begin{tabular}{|c|c|c|c|c|c|c|}
\hline & GARCH-N & GARCH-T & GARCH-GED & EGARCH-N & EGARCH-T & EGARCH-GED \\
\hline$\alpha_{0}$ & $\begin{array}{c}6.06 \mathrm{E}-06 \\
(2.840)\end{array}$ & $\begin{array}{l}2.60 \mathrm{E}-06 \\
(1.22672)\end{array}$ & $\begin{array}{c}4.57 \mathrm{E}-06 \\
(1.675)\end{array}$ & $\begin{array}{l}-0.61853 \\
(-4.5097)\end{array}$ & $\begin{array}{l}-8.53970 \\
(-10.221)\end{array}$ & $\begin{array}{l}-0.41123 \\
(-2.6373)\end{array}$ \\
\hline$\alpha_{1}$ & $\begin{array}{c}0.118255 \\
(4.676)\end{array}$ & $\begin{array}{l}0.067812 \\
(3.12508)\end{array}$ & $\begin{array}{c}0.088675 \\
(3.209)\end{array}$ & $\begin{array}{l}0.211580 \\
(4.09353)\end{array}$ & $\begin{array}{l}0.228418 \\
(3.04558)\end{array}$ & $\begin{array}{l}0.153991 \\
(2.65477)\end{array}$ \\
\hline$\beta$ & $\begin{array}{c}0.849330 \\
(31.02)\end{array}$ & $\begin{array}{l}0.917261 \\
(33.5515)\end{array}$ & $\begin{array}{c}0.883553 \\
(25.63)\end{array}$ & $\begin{array}{c}0.948440 \\
(68.281)\end{array}$ & $\begin{array}{l}0.042893 \\
(0.44643)\end{array}$ & $\begin{array}{l}0.967045 \\
(61.6744)\end{array}$ \\
\hline$\gamma$ & & & & $\begin{array}{l}-0.11095 \\
(-4.2543)\end{array}$ & $\begin{array}{l}-0.17706 \\
(-3.1632)\end{array}$ & $\begin{array}{l}-0.10029 \\
(-3.0082)\end{array}$ \\
\hline $\mathrm{V}$ & & $\begin{array}{l}5.530301 \\
(3.38426)\end{array}$ & $\begin{array}{c}1.358741 \\
(10.95)\end{array}$ & & $\begin{array}{l}15.31266 \\
(2.68352)\end{array}$ & $\begin{array}{l}1.360184 \\
(11.3896)\end{array}$ \\
\hline
\end{tabular}

Table 5. The quantile in different models.

\begin{tabular}{|c|c|c|c|}
\hline Distribution & DOF & Confidence level & Quantile \\
\hline \multirow{3}{*}{ GARCH-N } & & $95 \%$ & 1.645 \\
\hline & & & \\
\hline & & $99 \%$ & 2.330 \\
\hline \multirow{2}{*}{ GARCH-T } & & $95 \%$ & 1.97314 \\
\hline & 5.53 & $99 \%$ & 3.23413 \\
\hline \multirow{2}{*}{ GARCH-GED } & & $95 \%$ & 1.65163 \\
\hline & 1.36 & $99 \%$ & 2.56169 \\
\hline \multirow{2}{*}{ EGARCH-N } & & $95 \%$ & 1.645 \\
\hline & & $99 \%$ & 2.330 \\
\hline \multirow{2}{*}{ EGARCH-T } & & $95 \%$ & 1.55661 \\
\hline & 5.54 & $99 \%$ & 1.75551 \\
\hline \multirow{2}{*}{ EGARCH-GED } & & $95 \%$ & 1.65166 \\
\hline & 1.36 & $99 \%$ & 2.561 \\
\hline
\end{tabular}


Table 6. The comparison of the expected VaR failure rate and the actual results.

\begin{tabular}{cccccc}
\hline Confidence level & Model & Expectation & Actual results & Failure rate & LR statistic \\
\hline & GARCH-N & 24 & 39 & 0.08025 & 7.973732 \\
& GARCH-T & 24 & 28 & 0.05761 & 0.566508 \\
$95 \%$ & GARCH-GED & 24 & 39 & 0.08025 & 7.973732 \\
& EGARCH-N & 24 & 25 & 0.05144 & 0.021036 \\
& EGARCH-T & 24 & 31 & 0.06378 & 1.795374 \\
& EGARCH-GED & 24 & 40 & 0.08230 & 9.012279 \\
& GARCH-N & 5 & 19 & 0.03909 & 23.94891 \\
GARCH-T & 5 & 13 & 0.02675 & 9.440181 \\
$99 \%$ & GARCH-GED & 5 & 17 & 0.03498 & 18.60287 \\
& EGARCH-N & 5 & 16 & 0.03292 & 16.10955 \\
& EGARCH-T & 5 & 26 & 0.05350 & 45.86977 \\
& EGARCH-GED & 5 & 18 & 0.03704 & 21.21817 \\
\hline
\end{tabular}

EGARCH-N model, and then when the confidence level get to 99\%, EGARCH-N also can not been passed the test. Overall, the models we choose can not capture the risk of the copper futures market well, and more accurate models may be needed to describe the market risk.

\section{Conclusions}

In this paper, we use GARCH and EGARCH model to measure the the market risk of copper futures under the normal distribution , $\mathrm{T}$ distribution and GED distribution and predict trading VaR values at a certain confidence level .The conclusions are as followed: (1) The copper futures market has significant volatility clustering and need a long period to recover from the impact of unexpected events; (2) The impact of bad news on the futures market is greater than good news manifest the asymmetry of price shocks. And the price of Copper futures is so sensitive that small price declines could cause panic selling; (3) Yields series have some fat tail, while EGARCH-N model still can measure the market risk features more precisely than other models, but not at any level of confidence.

Thus, the empirical conclusions of this paper are not as expected by such two reasons: (1) VaR value is not a good description of the market tail risk, so that the error terms calculated by models describing the market volatility do not make the actual market risk consistent with VaR. (2) What VaR contained is only the market risk of copper futures, while the actual loss is a comprehensive reflection of all the risks, including market risk, credit risk and operational risk, which led VaR to underestimate the actual loss.

On the basis of our study, there are many topics can be continued in-depth, such as the effects of the volatility of other similarly commodity futures to the fluctuations of the studied future price, and the mutual influence between them. As well as in the different economic situation, with perspective of the association between commodity futures and stock markets, we also can study how the risk is dispersed and transferred between them.

\section{References}

[1] Dowd, K. (1998) Beyond Value-at-Risk: The New Science of Risk Management. John Wiley and Sons, New York.

[2] Christoffersen, P.F. and Errunza, V.R. (2000) Towards a Global Financial Architecture: Capital Mobility and Risk Management. Emerging Market Review, 1, 2-19.

[3] Bollerslev, T. (1986) Generalised Autoregressive Conditional Heteroskedasticy. Journal of Econometrics, 31, $307-327$. http://dx.doi.org/10.1016/0304-4076(86)90063-1

[4] Nelson, D.B. (1991) Conditional Heteroscedasticity in Asset Returns: A New Approach. Econometrica, 2, 347-370. http://dx.doi.org/10.2307/2938260 
[5] Anderson, F., Mausser, H., Rosen, D. and Uryasey, S. (2001) Credit Risk Optimization with Conditional Value-at-Risk Criterion. Mathematical Programming, 89, 273-291

[6] Rockafellar, R.T. and Uryasev, S. (2002) Conditional Value-at-Risk for General Loss Distributions. Journal of Banking and Finance, 26, 1443-1471. http://dx.doi.org/10.1016/S0378-4266(02)00271-6

[7] Alexander, S., Coleman, T. and Li, Y. (2006) Minimizing CVaR and VaR for a Portfolio of Derivatives. Journal of Banking and Finance, 30, 583-605. http://dx.doi.org/10.1016/j.jbankfin.2005.04.012 